\title{
Infant feeding in Sweden: Socio-demographic determinants and associations with adiposity in childhood and adolescence Andrej M Grjibovski ${ }^{1}$, Bettina Ehrenblad ${ }^{2}$ and Agneta Yngve*2
}

Address: ${ }^{1}$ Norwegian Institute of Public Health, Post Box 4404 Nydalen, N-0403 Oslo, Norway and ${ }^{2}$ Unit for Public Health Nutrition, Department of Biosciences and Nutrition, Karolinska Institutet, SE-141 57, Huddinge, Stockholm, Sweden

Email: Andrej M Grjibovski - andrei.grjibovski@fhi.no; Bettina Ehrenblad - bettina.ehrenblad@ki.se; Agneta Yngve* - agneta.yngve@ki.se

* Corresponding author

Published: 16 September 2008

International Breastfeeding Journal 2008, 3:23

doi:10.1 186/1746-4358-3-23

Received: 2 February 2007

Accepted: 16 September 2008

This article is available from: http://www.internationalbreastfeedingjournal.com/content/3/I/23

(c) 2008 Grjibovski et al; licensee BioMed Central Ltd.

This is an Open Access article distributed under the terms of the Creative Commons Attribution License (http://creativecommons.org/licenses/by/2.0), which permits unrestricted use, distribution, and reproduction in any medium, provided the original work is properly cited.

\begin{abstract}
Background: Recent reviews and meta-analyses conclude that breastfeeding constitutes a small but consistent protective effect against obesity or higher values of body mass index (BMI) in children, though in some studies this effect was weakened after adjustment for potential confounders. The aim of this study was to explore the socio-demographic determinants of the duration of breastfeeding in Sweden and the associations between breastfeeding duration and adiposity in childhood and adolescence.

Methods: This was a cross-sectional study of Swedish children. Height, weight and waist circumference were measured and the sum of five skin fold measurements were obtained in 11379- and 15-year old children. Breastfeeding data were retrospectively obtained from the medical records for 812 (7I.4\%) children. Multiple ordinal logistic regression was applied to study individual effects of the maternal characteristics on the duration of breastfeeding. The relationship between children's anthropometric characteristics and duration of breastfeeding was studied by multiple linear regression. Associations between the odds of being overweight or obese and the duration of breastfeeding were studied by multiple logistic regression. Both linear and logistic models were adjusted for children's age, gender, birth weight, maternal education and parental BMI in 1998 as well as maternal age and smoking status at childbirth.

Results: Maternal education was positively associated with the duration of breastfeeding in both 1983 and 1989. Non-smoking mothers were more likely to breastfeed longer than smokers in $1989(O R=1.9$, $95 \% \mathrm{Cl}$ : I.3, 3.0). Fifteen-year old children breastfed for shorter than 2 months had $1.2 \mathrm{~kg} / \mathrm{m}^{2}(95 \% \mathrm{Cl}: 0.1$, 2.4) higher BMI, $3.2 \mathrm{~cm}(95 \% \mathrm{Cl}: 0.2,6.2)$ higher waist circumference and $10.6 \mathrm{~mm}(95 \% \mathrm{Cl}$ : I.7, 19.6) higher sum of five skin fold measurements compared to those breastfed for 6 months or longer when adjusted for children's characteristics and maternal characteristics in 1998. Adjustment for maternal age and smoking status at childbirth weakened these associations to non-significant levels $\left(0.9 \mathrm{~kg} / \mathrm{m}^{2}, 95 \% \mathrm{Cl}:-0.4\right.$, 2.I; I.4 cm, 95\% Cl: $-1.5,4.4$ and $5.1 \mathrm{~mm}, 95 \% \mathrm{Cl}:-4.0,14.2$, respectively). In the 9 -year olds, the associations were less pronounced, but in the same direction. No trends between duration of breastfeeding and children's anthropometric characteristics were observed in any of the age groups.

Conclusion: Maternal education and smoking were significant predictors of breastfeeding duration in Sweden in the 1980s. Associations with measures of adiposity were observed only in 15-year old children between the children with shortest and longest breastfeeding duration, which were weakened after adjustment for maternal characteristics at childbirth.
\end{abstract}




\section{Background}

The importance of breastfeeding for both maternal and child health is widely recognised. Maternal short-term risks of not breastfeeding include increased risk of postpartum haemorrhage while long-term effects may include a higher risk of osteoporosis as well as breast and ovarian cancers [1]. Infants who are not breastfed have documented increased risk of infectious and atopic diseases and impaired psychomotor development [2]. The relationship between breastfeeding and obesity in childhood and adolescence is less clear [3]. Recent reviews and metaanalyses conclude that breastfeeding constitutes a small but consistent protective effect against obesity or higher values of body mass index (BMI) in children [4-7], though in some studies this effect was weakened after adjustment for potential confounders [7-12]. Studies which estimate the effects of exclusive breastfeeding on childhood obesity also suggest a protective effect [11], although this effect was not found in some ethnic groups or in smokers [12]. Considerable heterogeneity in definitions and duration of breastfeeding, criteria for overweight and obesity, age of children when the measurements were taken, and confounding factors used for adjustment, could contribute to the inconsistencies in the results of the studies. Selective reporting and publication bias could also influence the available evidence.

Most of the studies on the effect of infant feeding on overweight and obesity have used BMI as the main outcome. However, it is body adiposity, rather than weight in relation to height, that is related to the obesity-associated diseases. Skin fold measurements provide better assessment of adiposity than BMI [13]. Studies that used skin folds as a measure of obesity in relation to breastfeeding were small and yielded inconsistent results $[12,14,15]$. Moreover, Burdette et al found no relationship between the duration of breastfeeding and adiposity in 5-year old children using dual-energy X-ray absorptiometry (DXA) and suggested that the effect of breastfeeding on obesity may vary depending on the measure of adiposity used [16]. Thus, there is a need for further research on the role of breastfeeding as protection against childhood and adolescent obesity using other measures of adiposity than BMI.

Sweden is a country with almost universal initiation and long duration of breastfeeding compared to other industrialised nations [17]. The initiation and duration of breastfeeding depend on a number of determinants, which could be summarised in five groups: socio-demographic, psychosocial, biomedical and health care-related factors, community attributes, and public policy [18]. However, the importance of these factors varies across countries and over time [19]. We identified only one study specifically addressing socio-economic determinants of breastfeeding in Sweden [20]. However, this study reports the determinants of exclusive breastfeeding only. Other studies have reported that duration of any breastfeeding in Sweden was positively associated with maternal education, inversely with smoking and not associated with maternal age $[21,22]$.

Our study aims to estimate the effects of selected sociodemographic factors on the duration of breastfeeding in Sweden and to study the associations between the duration of breastfeeding and adiposity in childhood and adolescence using data from a Swedish study of children and adolescents and from medical records.

\section{Methods}

This study was performed as an extension of a cross-sectional survey performed in 1998. The sample included 1137 children born in 1983 and 1989 from randomly selected schools in two areas in central Sweden, namely, Södertörn (Southern Stockholm) and Örebro [23].

\section{Data collection}

The data on infant feeding status of the participants at 2 weeks, 2, 4, and 6 months as well as their birth weight were retrospectively collected from the paediatric files at local health care centres one year after the survey. These time points were selected to ensure comparability of our data with the national statistics [17]. The term breastfeeding here refers to any breastfeeding at the specified time points.

Data on all other studied factors were collected in 1998. Body weight was measured to the nearest $0.1 \mathrm{~kg}$ on a SECA digital beam balance, calibrated after transportation. Height was measured to the nearest $5 \mathrm{~mm}$, using a Harpenden transportable stadiometer. The subjects were dressed in light underwear and no shoes. Overweight (including obesity) was defined using the International Obesity Task Force (IOTF) cut-off criteria [24]. Later in the text, the term overweight is used to cover overweight including obesity. Biceps, triceps, subscapular, suprailiac, and calf skin fold thickness was measured using Harpenden calipers according to Lohman [25]. The sum of all five skin fold measurements (in $\mathrm{mm}$ ) was calculated. Waist circumference (in $\mathrm{cm}$ ) was measured using a metal anthropometric tape midway between the lower rib margin and the iliac crest, at the end of gentle expiration. Pubertal maturation was assessed according to Tanner [26]. Further details on sampling procedure, participation rates and data collection are presented elsewhere [23].

The data on parental height, weight and maternal education in 1998 as well as on maternal age and smoking status at the time of childbirth were obtained from the parents' questionnaire. Education was categorised as basic (9 years), high school (11-12 years) and university educa- 
tion. By smoking status at childbirth, women were categorized as non-smokers or smokers using the reported data on age at initiation and cessation of smoking. Maternal age at childbirth was divided in to three categories: < 25 years, $25-34$, and $\geq 35$ years. Maternal and paternal BMI were calculated using the self-reported height and weight data.

\section{Data analysis}

Differences between breastfeeding rates in 1983 and 1989 were compared by log-rank tests in Kaplan-Meier analysis. Individual effects of each of the maternal socio-demographic characteristics on the duration of breastfeeding were assessed using multiple ordinal logistic regression analysis given the ordinal nature of the dependent variable. Odds ratios (OR) with 95\% confidence intervals (CI) were calculated. OR above one suggests higher odds for longer breastfeeding. Maternal basic education, age of 35 years or older, smoking during pregnancy and female gender of the baby were used as reference categories.

Given that very few children were never breastfed, four categories of the duration of breastfeeding were used in all other analyses: $<2$ months, $2-3$ months, $4-5$ months and $\geq 6$ months. Independent effects of breastfeeding on the studied anthropometric parameters were assessed using multiple linear regression. Logistic regression was used to study the associations between the duration of breastfeeding and overweight at 9 and 15 years. Child age, gender and Tanner stage of pubertal maturation, maternal education, maternal and paternal BMI at the time of the study were used as covariates in the first model. In the second model, additional adjustment for maternal age and smoking status at childbirth was made. Tests for trends were performed by introducing the duration of breastfeeding in the models as a continuous variable. All analyses were performed using SPSS, version 13.0. (SPSS Inc., Chicago, IL). Analyses were performed separately in 9and 15-year old children.

Approval for the cross-sectional survey and for the breastfeeding data collection and analysis were obtained from the local Medical Ethics' committees in Stockholm and Örebro.

\section{Results}

The data on breastfeeding were available for 812 (71.4\%) of the 1137 subjects enrolled in the study. No differences by education, age, smoking status and gender of the children were found between mothers with missing and available data on breastfeeding within the year of childbirth except for the slightly higher proportion of younger mothers in the group with missing data on breastfeeding in those who gave birth in $1983(\mathrm{p}=0.04)$. Maternal and children's characteristics for the participants with available data on breastfeeding are presented in Table 1.

\section{Breastfeeding rates and correlates of breastfeeding duration}

The rates of breastfeeding at 2 weeks, 2, 4 and 6 months are presented in Figure 1. Women who gave birth in 1983 were more likely to breastfeed longer than those who gave birth in 1989 ( $\mathrm{p}=0.05)$. Maternal education was positively associated with longer duration of breastfeeding in both 1983 and 1989 (Table 2). The variations were more pronounced in 1983. Non-smokers were more likely to breastfeed longer than smokers in 1989, according to the recall data on smoking. The associations between breastfeeding duration and smoking in 1983 were in the same direction. Boys were breastfed for a shorter time than girls in 1989, while no differences were observed in 1983.

\section{Duration of breastfeeding and measures of adiposity}

Both 9- and 15-year old children from the group with the shortest breastfeeding duration had the highest values of BMI, waist circumference and sum of five skin fold measurements (Table 3). In crude analyses, 15-year old children who were breastfed for less than 2 months had higher BMI and waist circumferences than their counterparts who were breastfed for 6 or more months. Moreover, we observed inverse trends between duration of breastfeeding and both BMI and waist circumference. The differences in sum of skin fold measurements were even more pronounced, but did not reach the level of statistical significance due to greater variability. The pattern was similar for the 9-year old children, although less pronounced and not reaching the level of statistical significance (Table 4).

Adjustment for children's characteristics and parental data at the time of the study only marginally changed the findings. Fifteen-year old children who were breastfed for shorter than 2 months had higher values for BMI, waist circumference and sum of five skin fold measurements by $1.2 \mathrm{~kg} / \mathrm{m}^{2}, 3.2 \mathrm{~cm}$, and $10.6 \mathrm{~mm}$, respectively, compared to children who were breastfed for 6 months or longer. Children from the same age group who were breastfed for 2-3 months had $6.1 \mathrm{~mm}$ lower sum of skin fold measurements than the reference group. Similar, but non-significant associations were observed in 9-year old children.

Adjustment for maternal age and smoking status at childbirth weakened all previously described associations to non-significant levels. Fifteen-year old children who were breastfed for shorter than 2 months continued to have higher values for BMI, waist circumference and sum of skin fold measurements compared to the reference group, although the differences were reduced by about one third for BMI and by half for other measures. The only signifi- 
Table I: Characteristics of mothers and their children with available data on breastfeeding by the children's birth year

\begin{tabular}{|c|c|c|}
\hline & $\begin{array}{c}1983 \\
(n=394)\end{array}$ & $\begin{array}{c}1989 \\
(n=418)\end{array}$ \\
\hline \multicolumn{3}{|l|}{ Maternal characteristics } \\
\hline \multicolumn{3}{|l|}{ Age at childbirth, n (\%) } \\
\hline$<25$ & $85(21.6)$ & $60(14.4)$ \\
\hline $25-34$ & $212(53.8)$ & $217(51.9)$ \\
\hline $35+$ & $47(11.9)$ & $43(10.3)$ \\
\hline Unknown & $50(12.7)$ & $98(23.4)$ \\
\hline \multicolumn{3}{|l|}{ Education, n (\%) } \\
\hline Basic & $76(19.3)$ & $60(14.4)$ \\
\hline High school & $139(35.3)$ & $222(53.1)$ \\
\hline University & $160(40.6)$ & $120(28.7)$ \\
\hline Unknown & $19(4.8)$ & $16(3.8)$ \\
\hline \multicolumn{3}{|l|}{ Smoking at childbirth, n (\%) } \\
\hline Non-smokers & $20 I(5 I .0)$ & $182(43.5)$ \\
\hline Smokers & $145(36.8)$ & $140(33.5)$ \\
\hline Unknown & $48(12.2)$ & $96(23.0)$ \\
\hline \multicolumn{3}{|l|}{ Parents' BMI } \\
\hline Current maternal BMI, M (SD) & $24.1(3.9)$ & $23.8(3.9)$ \\
\hline Current paternal BMI, M (SD) & $25.7(3.0)$ & $25.6(3.2)$ \\
\hline \multicolumn{3}{|l|}{ Children's characteristics } \\
\hline \multicolumn{3}{|l|}{ Gender, n (\%) } \\
\hline Boys & $176(44.7)$ & $208(49.8)$ \\
\hline Girls & $218(55.3)$ & $210(50.2)$ \\
\hline Age, M (SD) & I5.5 (0.4) & $9.6(0.3)$ \\
\hline Overweight, n (\%) & $43(10.9)$ & $64(15.3)$ \\
\hline $\mathrm{BMI}, \mathrm{kg} / \mathrm{m}^{2}, \mathrm{M}(\mathrm{SD})$ & $20.7(2.6)$ & $17.4(2.5)$ \\
\hline Waist circumference, cm, M (SD) & $71.2(6.8)$ & $60.8(6.4)$ \\
\hline Sum of five skin fold measurements, mm, M (SD) & $53.0(21.2)$ & $46.2(21.2)$ \\
\hline
\end{tabular}

cant association was observed for 15-year old children who were breastfed for 2-3 months, who had $6.9 \mathrm{~cm}$ lower sum of skin fold measurements than the reference group. No trends between the duration breastfeeding and

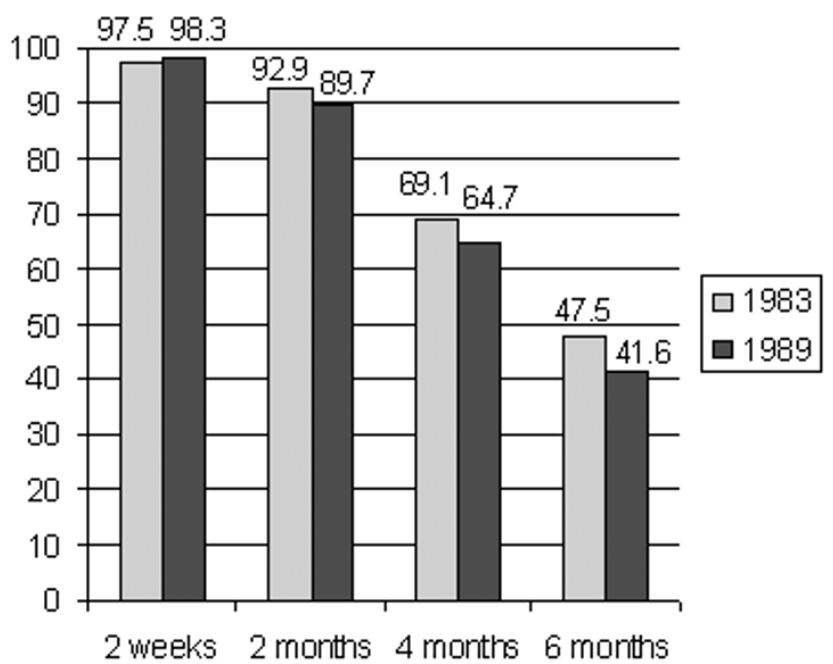

Figure I

Proportion of children (\%) breastfed at 2 weeks, 2, 4 and 6 months of age. children's anthropometric indices were observed (Table 4).

Table 2: Adjusted odds ratios* (OR) for longer breastfeeding by maternal characteristics

\begin{tabular}{|c|c|c|}
\hline & 1983 & 1989 \\
\hline & OR (95\% Cl) & OR (95\% Cl) \\
\hline \multicolumn{3}{|c|}{ Maternal education } \\
\hline University & $4.73(2.69,8.30)$ & $2.15(1.11,4.15)$ \\
\hline High school & $2.73(1.70,4.4 I)$ & $1.26(0.78,2.05)$ \\
\hline Basic & 1.00 (Reference) & I.00 (Reference) \\
\hline \multicolumn{3}{|c|}{ Maternal smoking } \\
\hline No & $1.49(0.98,2.26)$ & $1.94(1.27,2.97)$ \\
\hline Yes & I.00 (Reference) & I.00 (Reference) \\
\hline \multicolumn{3}{|l|}{ Maternal age } \\
\hline$<25$ & $0.92(0.45,1.90)$ & I.7I $(0.81,3.63)$ \\
\hline $25-34$ & $1.16(0.61,2.18)$ & $1.30(0.69,2.45)$ \\
\hline$\geq 35$ & I.00 (Reference) & 1.00 (Reference) \\
\hline \multicolumn{3}{|c|}{ Gender of the baby } \\
\hline Boy & $1.05(0.70,1.57)$ & $0.66(0.44,0.99)$ \\
\hline Girl & 1.00 (Reference) & 1.00 (Reference) \\
\hline
\end{tabular}

*Adjusted for all variables in the table. 
Table 3: Children's anthropometric characteristics (mean values, with standard deviation in brackets) by duration of breastfeeding

\begin{tabular}{|c|c|c|c|c|c|c|}
\hline \multirow[b]{2}{*}{$\begin{array}{l}\text { Duration of } \\
\text { breastfeeding }\end{array}$} & \multicolumn{3}{|c|}{ I5-year old children } & \multicolumn{3}{|c|}{ 9-year old children } \\
\hline & BMI, kg/m² & $\begin{array}{c}\text { Waist } \\
\text { circumference, } \\
\mathbf{c m}\end{array}$ & $\begin{array}{l}\text { Sum of five skin } \\
\text { folds, } \mathrm{mm}\end{array}$ & BMI, $\mathrm{kg} / \mathrm{m}^{2}$ & $\begin{array}{c}\text { Waist } \\
\text { circumference, } \\
\mathbf{c m}\end{array}$ & $\begin{array}{l}\text { Sum of five skin } \\
\text { folds, } \mathrm{mm}\end{array}$ \\
\hline$<2$ months & $21.8(3.8)$ & $75.3(11.2)$ & $59.8(28.2)$ & $17.7(3.4)$ & $62.2(9.1)$ & $47.9(29.8)$ \\
\hline $2-3$ months & $20.6(2.6)$ & $70.3(6.2)$ & $53.1(24.0)$ & $17.3(2.3)$ & $60.9(5.8)$ & $45.1(19.2)$ \\
\hline $4-5$ months & $20.6(2.4)$ & $71.6(5.8)$ & $53.5(21.9)$ & $17.3(2.4)$ & $60.2(6.3)$ & $46.8(22.9)$ \\
\hline$\geq 6$ months & $20.7(2.4)$ & $70.8(6.5)$ & $51.7(22.5)$ & $17.3(2.5)$ & $60.8(6.2)$ & $46.0(19.2)$ \\
\hline
\end{tabular}

\section{Duration of breastfeeding and overweight}

Altogether, $10.9 \%$ (95\%CI: 8.2, 14.4) of 15 -year old and $15.3 \%$ (95\%CI: $12.2,19.1$ ) of 9 -year old children were overweight. In the group with the shortest duration of breastfeeding, the proportion of overweight was $25.0 \%$ in the 15 -year old and $20.5 \%$ in the 9-year old children while in the group with the longest duration of breastfeeding, the corresponding proportions were $9.7 \%$ and $14.6 \%$ (Table 5). In crude analysis, 15-year old children who were breastfed for less than 2 months had considerably higher odds for being overweight ( $\mathrm{OR}=3.1,95 \% \mathrm{CI}: 1.2$, 8.3) than those who were breastfed for 6 months or longer.

Adjustment for children's data, maternal education and parental BMI at the time of the study weakened this association to $\mathrm{OR}=2.2(95 \% \mathrm{CI}: 0.6,7.7)$. Further adjustment for maternal age and smoking status at childbirth further reduced this odds ratio to $\mathrm{OR}=1.0$ (95\%CI: 0.2, 5.6). Other results in this age group remained largely unchanged.
In 9-year old children, the odds of being overweight were $50 \%$ higher for the group with the shortest duration of breastfeeding in crude analysis, but the CI were wide and included 1. Adjustment for other factors further weakened this association. Moreover, children who were breastfed for 2-3 and 4-5 months tended to have lower odds of being overweight compared to the reference group.

\section{Discussion}

The results suggest that in spite of the egalitarian nature of the Swedish society, there were considerable variations in the duration of breastfeeding by maternal education and smoking status during the 1980s. Moreover, we found that the children who were breastfed for shorter than 2 months had higher values for BMI, waist circumference and sum of five skin fold measurements at 15 year compared to their counterparts who were breastfed for 6 months or longer independently of birth weight, age, gender, parental BMI and maternal education. However, adjustment for maternal age and smoking at childbirth substantially reduced these associations. No doseresponse relationship between the duration of breastfeed-

Table 4: Crude and adjusted differences with $95 \%$ confidence intervals $(\mathrm{Cl})$ in $\mathrm{BMI}$, waist circumference and sum of five skin folds by duration of breastfeeding.

\begin{tabular}{|c|c|c|c|c|c|c|}
\hline & \multicolumn{3}{|c|}{ I5-years old children } & \multicolumn{3}{|c|}{ 9-years old children } \\
\hline & BMI, kg/m² & $\begin{array}{c}\text { Waist } \\
\text { circumference, } \mathrm{cm}\end{array}$ & $\begin{array}{l}\text { Sum of five skin } \\
\text { folds, } \mathrm{mm}\end{array}$ & BMI, kg/m² & $\begin{array}{c}\text { Waist } \\
\text { circumference, } \mathrm{cm}\end{array}$ & $\begin{array}{l}\text { Sum of five skin } \\
\text { folds, } \mathrm{mm}\end{array}$ \\
\hline \multicolumn{7}{|l|}{ Crude } \\
\hline$<2$ months & I.2 (0.I, 2.2) & $4.5(1.7,7.4)$ & $8.1(-1.4,18.1)$ & $0.4(-0.5,1.2)$ & I.3 $(-0.9,3.4)$ & I.5 $(-5.7,8.7)$ \\
\hline $2-3$ months & $-0.1(-0.8,0.5)$ & $-0.5(-2.3,1.3)$ & $1.4(-4.7,7.6)$ & $0(-0.6,0.6)$ & $0.1(-1.5,1.7)$ & $-0.8(-6.1,4.4)$ \\
\hline 4-5 months & $-0.1(-0.8,0.6)$ & $0.9(-1.0,2.7)$ & I.8 $(-4.7,8.4)$ & $0(-0.6,0.6)$ & $-0.5(-2.1,1.1)$ & $0.6(-4.7,6.0)$ \\
\hline $6+$ months & Reference & Reference & Reference & Reference & Reference & Reference \\
\hline $\mathrm{p}$-value for trend & 0.033 & 0.003 & 0.129 & 0.485 & 0.242 & 0.864 \\
\hline \multicolumn{7}{|l|}{ Adjusted } \\
\hline$<2$ months & $1.2(0.1,2.4)$ & $3.2(0.2,6.2)$ & $10.6(1.7,19.6)$ & $0.5(-0.4,1.5)$ & I.8 $(-0.5,4.1)$ & $3.2(-4.7,11.0)$ \\
\hline $2-3$ months & $-0.4(-1.1,0.3)$ & $-0.8(-2.6,1.1)$ & $-6.1(-11.8,-0.4)$ & $-0.1(-0.7,0.6)$ & $0.2(-1.6,2.0)$ & $-1.9(-7.6,3.9)$ \\
\hline $4-5$ months & $-0.2(-0.9,0.5)$ & $0.5(-1.3,2.4)$ & $0.7(-4.9,6.2)$ & $0.1(-0.6,0.8)$ & $0.1(-1.7,1.8)$ & $1.4(-4.3,6.9)$ \\
\hline $6+$ months & Reference & Reference & Reference & Reference & Reference & Reference \\
\hline $\mathrm{p}$-value for trend & 0.725 & 0.439 & 0.973 & 0.485 & 0.242 & 0.864 \\
\hline
\end{tabular}

*Adjusted for children's age, gender, pubertal maturation, birthweight, maternal education, maternal and paternal BMI 
Table 5: Prevalence of overweight, crude and adjusted odds ratios (OR) with $95 \%$ confidence intervals (CI) for overweight by duration of breastfeeding

\begin{tabular}{|c|c|c|c|c|}
\hline Duration of breastfeeding & $\begin{array}{l}\text { \% Overweight } \\
\text { (95\% Cl) }\end{array}$ & $\begin{array}{l}\text { Crude OR } \\
(95 \% \mathrm{Cl})\end{array}$ & $\begin{array}{l}\text { Adjusted OR* } \\
(95 \% \mathrm{Cl})\end{array}$ & $\begin{array}{l}\text { Adjusted OR } \\
(95 \% \mathrm{Cl})\end{array}$ \\
\hline \multicolumn{5}{|l|}{ | 5-year-olds } \\
\hline$<2$ months & $25.0(12.7,43.5)$ & $3.1(1.2,8.3)$ & $2.2(0.6,7.7)$ & $1.0(0.2,5.6)$ \\
\hline $2-3$ months & $10.6(5.9,18.5)$ & I.I $(0.5,2.5)$ & $0.6(0.2,1.7)$ & $0.6(0.2,2.2)$ \\
\hline 4-5 months & $9.4(4.9,17.5)$ & $1.0(0.4,2.3)$ & $0.9(0.4,2.3)$ & I.0 $(0.3,3.3)$ \\
\hline$\geq 6$ months & $9.7(6.2,14.8)$ & Reference & Reference & Reference \\
\hline $\mathrm{p}$-value $\ddagger$ & & 0.102 & 0.359 & 0.881 \\
\hline $\mathrm{p}$-value for trend§ & & 0.107 & 0.966 & 0.688 \\
\hline \multicolumn{5}{|l|}{ 9-year-olds } \\
\hline$<2$ months & $20.9(11.5,35.3)$ & I.5 $(0.7,3.5)$ & $1.5(0.6,3.9)$ & I.2(0.3, 4.6) \\
\hline $2-3$ months & $12.5(7.5,20.2)$ & $0.8(0.4,1.7)$ & $0.7(0.3,1.6)$ & $0.6(0.2,1.7)$ \\
\hline 4-5 months & $17.7(11.4,26.6)$ & $1.2(0.6,2.5)$ & $1.2(0.6,2.6)$ & $0.5(0.1,1.5)$ \\
\hline$\geq 6$ months & $14.5(10.1,20.6)$ & Reference & Reference & Reference \\
\hline $\mathrm{P}$-value $\ddagger$ & & 0.538 & 0.501 & 0.430 \\
\hline$p$-value for trend $\S$ & & 0.673 & 0.977 & 0.745 \\
\hline
\end{tabular}

*Adjusted for children's age, gender, pubertal maturation, birth weight, maternal education, maternal and paternal BMI

$\dagger+$ maternal age and smoking status at childbirth

łPerformed by Pearson's $\chi^{2}$ test in univariate analysis and Wald test in logistic regression

$\S$ Performed by introducing breastfeeding categories in the model as a continuous variable

ing and any of the studied measures of adiposity were found. We also observed that 15 -year old children who were breastfed for shorter than 2 months had 3 times higher odds of being overweight than their counterparts breastfed for more than 6 months in a crude analysis, but this association disappeared after adjustment for other factors. The associations for 9-year olds were in the same direction, although they were less pronounced and did not reach the level of statistical significance.

The representativeness of the sample in relation to the general population in the studied areas [23], prospective registration of the breastfeeding status by health professionals, objective measurements of children's and adolescents' anthropometric characteristics are the main strengths of the study. No differences in socio-demographic factors between mothers with available and missing data on breastfeeding suggest that our estimates of breastfeeding prevalence are likely to be valid for the studied areas. The national breastfeeding statistics for 1989 reported the prevalence of any breastfeeding to be $97.7 \%$, $85.8 \%, 67.7 \%$, and $49.8 \%$ at 2 weeks, 2,4 , and 6 months, respectively, which is slightly above our estimates at 4 and 6 months $(98.3 \%, 89.7 \%, 64.7 \%$, and $41.6 \%)$. This is not surprising given that the studied areas were consistently reported to have breastfeeding rates below the national average [17] in previous national surveys.

Socio-demographic factors are important determinants of breastfeeding $[18,19]$. Our findings on variations in breastfeeding duration by maternal education are in line with the results of other studies carried out in Sweden, which also found that low education was associated with shorter duration of breastfeeding [20,21]. Maternal education in this study is defined as the highest attained education, not education at childbirth. This might be a better indicator reflecting the educational potential of the mother, her ambitions and the possibility of studying after childbirth. The underlying mechanisms of the associations between education and duration of breastfeeding are unclear; though we hypothesize that better educational potential of the mothers might lead to better compliance to the recommendations provided by the health care staff regarding breastfeeding. Although education is considered to be the most informative indicator of women's socioeconomic status in Sweden, there is still a chance for residual confounding by other factors. One study from Sweden reported no association between maternal age and duration of breastfeeding, which is in line with our results [22]. There is convincing evidence that smoking is associated with shorter duration of breastfeeding $[19-22,27,28]$. We obtained similar associations in the present study.

The self-reported nature of the maternal data may threaten the validity of the study, although this is unlikely given that previous studies from Sweden reported acceptable validity of self-reported data on obesity in women [29] and smoking during pregnancy [30]. Moreover, the prevalence of smoking in pregnancy in Sweden was about $30 \%$ during the 1980 s with some tendency to decrease during the decade [31]. Our data show the prevalence of smoking to be $37 \%$ and $34 \%$ in 1983 and 1989 , respectively, suggesting that underestimation is unlikely. 
Similarly to most studies, our findings suggest that infants who are breastfed for shorter than 2 months have higher BMI, larger waistline and thicker skin fold measurements at 15 year than their counterparts breastfed for 6 months or more [3-8,32,33], but only before adjustment for maternal age and smoking at the time of childbirth. Several other studies also report attenuation of crude associations between measures of adiposity and breastfeeding after adjustment for confounders [6,8-11]. No doseresponse effect of the duration of breastfeeding on any of the studied measures of adiposity in either 9- or 15-year old children was observed. Interestingly, after adjustment, the lowest values for all measures of adiposity in both 15and 9-year old children were observed in the group breastfed for 2-3 months reaching the level of statistical significance for sum of skin fold measurements in 15-year-olds.

Similarly to what was observed for the continuous measures of adiposity, crude associations between breastfeeding and overweight were substantially reduced after adjustment for maternal age and smoking status at childbirth. Moreover, adjustment for other studied characteristics resulted in lower odds ratios for overweight for 15year old children breastfed for 2-3 months $(\mathrm{OR}=0.7$, 95\%CI: $0.2,2.2)$ and for 9 year old children breastfed for both 2-3 (OR $=0.6,95 \%$ CI: $0.2,1.7)$ and $4-5$ months $(\mathrm{OR}=0.5,95 \% \mathrm{CI}: 0.1,1.5)$. Although the results were not statistically significant, they are congruent with the results of the analyses performed on BMI, waist circumference and sum of skin fold measurements. Victora et al also found $50 \%$ reduction in obesity in children breastfed for 3-5 months making it tempting to relate all these findings to the "critical window" theory of development [9]. However, wide confidence intervals for all associations in our study do not allow any conclusions.

The results of the study should be interpreted with caution, taking into account the limitations of the study. Firstly, the small sample size leads to insufficient statistical power to detect small differences in adiposity measures and odds for overweight by breastfeeding status. Secondly, the use of multiple linear regression while analysing slightly skewed data on BMI, waist circumference and skin fold measurements might be criticized. However, the distributions of the residuals were approximately normal and other assumptions were not violated. Moreover, repeated analyses on logarithmically transformed data yielded similar results.

Although our results do not contradict conclusions of large meta-analyses and systematic reviews on the effect of breastfeeding on obesity in childhood and adolescents, less pronounced differences between the groups of breastfeeding duration may partly be explained by the choice of the reference group. While in often cited reviews $[4,6]$ and meta-analyses the reference group included formula fed infants, in our study, the reference group was different. Contrary to many other studies, the proportion of never breastfed infants in our setting was very small. Only $2.5 \%$ of 15 -year old and $1.8 \%$ of 9-year old children in our sample were not breastfeed at 2 weeks (Figure 1). Thus, our reference group included children, most of who were breastfed, but for shorter period than two months. Moreover, given that initiation rates and average duration of breastfeeding in Sweden are greater and the prevalence of childhood overweight and obesity is lower than in many other European countries and the USA, the associations between breastfeeding duration and later adiposity may be less visible in Sweden than in countries where breastfeeding is less popular and childhood obesity is more prevalent.

\section{Conclusion}

In conclusion, we observed considerable social variations in breastfeeding duration in Sweden during the 1980s, and found that 15 -year old adolescents, who were breastfed for less than 2 months, had a higher BMI, larger waist circumference and sum of five skin fold measurements compared to their counterparts who were breastfed for 6 months or longer, although the associations were no longer significant after adjustment for maternal age and smoking status at childbirth. Similar, but less pronounced associations were observed in 9-year old children. We could not replicate previously reported dose-response associations between the duration of breastfeeding and measures of adiposity or prevalence of overweight. Thus the results are generally in the expected direction, but inconclusive and should be interpreted and generalized with caution, given the limitations of the study design and almost universal initiation of breastfeeding in Sweden.

\section{Competing interests}

The authors declare that they have no competing interests.

\section{Authors' contributions}

AMG drafted the manuscript and performed the statistical analysis. BE helped to design the study, collected the breastfeeding data from the medical records and entered these into the data base. AY conceived the study, participated in its design and coordination and drafted the manuscript. All authors approved the final manuscript.

\section{Acknowledgements}

Dr Anita Hurtig-Wennlöf and Mr Eric Poortvliet helped collect the anthropometric data from the children. The collection of data in 1998 was funded jointly by the Stockholm County Council and the Karolinska Institutet.

\section{References}

I. Heinig MJ, Dewey KG: Health advantages of breastfeeding for mothers: a critical review. Nutrition Research Reviews 1997, 10:35-56. 
2. Heinig MJ, Dewey KG: Health advantages of breastfeeding for infants: a critical review. Nutrition Research Reviews 1996, 9:89-110.

3. Schack-Nielsen L, Michaelsen KF: Breast feeding and future health. Curr Opin Clin Nutr Metab Care 2006, 9:289-296.

4. Arenz S, Ruckerl R, Koletzko B, von Kries R: Breast-feeding and childhood obesity - a systematic review. Int J Obes Relat Metab Disord 2004, 28: 1247-1256.

5. Harder T, Bergmann R, Kallischnigg G, Plagemann A: Duration of breastfeeding and risk of overweight: a meta-analysis. Am J Epidemiol 2005, 162:397-403.

6. Owen CG, Martin RM, Whincup PH, Davey-Smith G, Gillman MW, Cook DG: The effect of breastfeeding on mean body mass index throughout life: a quantitative review of published and unpublished observational evidence. Am J Clin Nutr 2005, 82:1298-1307.

7. Owen CG, Martin RM, Whincup PH, Smith GD, Cook DG: Effect of infant feeding on the risk of obesity across the life course: a quantitative review of published evidence. Pediatrics 2005, I I 5: 1367-1377.

8. Li L, Parsons TJ, Power C: Breast feeding and obesity in childhood: cross sectional study. BMJ 2003, 327:904-905.

9. Victora CG, Barros F, Lima RC, Horta BL, Wells J: Anthropometry and body composition of 18 year old men according to duration of breast feeding: birth cohort study from Brazil. $B M$ J 2003, 327:90I.

10. Shields L, O'Callaghan M, Williams GM, Najman JM, Bor W: Breastfeeding and obesity at 14 years: a cohort study. J Paediatr Child Health 2006, 42:289-296.

II. Gillman MW, Rifas-Shiman SL, Camargo CA Jr, Berkey CS, Frazier AL, Rockett HR, Field $A E$, Colditz GA: Risk of overweight among adolescents who were breastfed as infants. JAMA 200I, 285:246I-2467.

12. Bogen DL, Hanusa BH, Whitaker RC: The effect of breast-feeding with and without formula use on the risk of obesity at 4 years of age. Obes Res 2004, I 2:1527-1535.

13. Nevill AM, Stewart AD, Olds T, Holder R: Relationship between adiposity and body size reveals limitations of BMI. Am J Phys Anthropol 2006, 129:151-156.

14. Zive MM, McKay H, Frank-Spohrer GC, Broyles SL, Nelson JA, Nader PR: Infant-feeding practices and adiposity in 4-y-old Angloand Mexican-Americans. Am / Clin Nutr 1992, 55: I I04-I I 08.

15. Bergmann KE, Bergmann RL, Von Kries R, Bohm O, Richter R, Dudenhausen JW, Wahn U: Early determinants of childhood overweight and adiposity in a birth cohort study: role of breast-feeding. Int J Obes Relat Metab Disord 2003, 27:162-172.

16. Burdette HL, Whitaker RC, Hall WC, Daniels SR: Breastfeeding, introduction of complementary foods, and adiposity at $5 \mathbf{y}$ of age. Am J Clin Nutr 2006, 83:550-558.

17. Breastfeeding, children born 2003. Stockholm, Sweden: Centre of Epidemiology, the National Board of Health and Welfare; 2005.

18. Yngve A, Sjostrom M: Breastfeeding determinants and a suggested framework for action in Europe. Public Health Nutr 200I, 4:729-739.

19. Rogers IS, Emmett PM, Golding J: The incidence and duration of breast feeding. Early Hum Dev 1997, 49(Suppl):S45-74.

20. Ludvigsson JF, Ludvigsson J: Socio-economic determinants, maternal smoking and coffee consumption, and exclusive breastfeeding in $\mathbf{1 0 2 0 5}$ children. Acta Paediatr 2005, 94:1310-1319.

21. Ekstrom A, Widstrom AM, Nissen E: Duration of breastfeeding in Swedish primiparous and multiparous women. J Hum Lact 2003, 19:172-178.

22. Kull I, Wickman M, Lilja G, Nordvall SL, Pershagen G: Breast feeding and allergic diseases in infants-a prospective birth cohort study. Arch Dis Child 2002, 87:478-48I.

23. Wennlof AH, Yngve A, Sjostrom M: Sampling procedure, participation rates and representativeness in the Swedish part of the European Youth Heart Study (EYHS). Public Health Nutr 2003, 6:291-299.

24. Cole TJ, Bellizzi MC, Flegal KM, Dietz WH: Establishing a standard definition for child overweight and obesity worldwide: international survey. BM/ 2000, 320:1240-1243.

25. Lohman TG, Roche AF, Martorell R, Ed: Anthropometric Standardization Reference Manual. Champaign, Illinois: Human Kinetics; 1988.
26. Tanner J: Growth at adolescence Oxford, Uk: Blackwell; 1962

27. Horta BL, Kramer MS, Platt RW: Maternal smoking and the risk of early weaning: a meta-analysis. Am J Public Health 200I, 91:304-307.

28. Amir LH, Donath SM: Does maternal smoking have a negative physiological effect on breastfeeding? The epidemiological evidence. Birth 2002, 29: I | 2-1 23.

29. Nyholm M, Gullberg B, Merlo J, Lundqvist-Persson C, Rastam L, Lindblad U: The validity of obesity based on self-reported weight and height: Implications for population studies. Obesity (Silver Spring) 2007, I5:197-208.

30. George L, Granath F, Johansson AL, Cnattingius S: Self-reported nicotine exposure and plasma levels of cotinine in early and late pregnancy. Acta Obstet Gynecol Scand 2006, 85: I33।-1337.

3I. Odlind V, Haglund B, Pakkanen M, Otterblad Olausson P: Deliveries, mothers and newborn infants in Sweden, 1973-2000. Trends in obstetrics as reported to the Swedish Medical Birth Register. Acta Obstet Gynecol Scand 2003, 82:5। 6-528.

32. Butte NF, Wong WW, Hopkinson JM, Smith EO, Ellis KJ: Infant feeding mode affects early growth and body composition. Pediatrics 2000, 106: I355-1366.

33. Tulldahl J, Pettersson K, Andersson SW, Hulthen L: Mode of infant feeding and achieved growth in adolescence: early feeding patterns in relation to growth and body composition in adolescence. Obes Res 1999, 7:431-437.

Publish with Bio Med Central and every scientist can read your work free of charge

"BioMed Central will be the most significant development for disseminating the results of biomedical research in our lifetime. "

Sir Paul Nurse, Cancer Research UK

Your research papers will be:

- available free of charge to the entire biomedical community

- peer reviewed and published immediately upon acceptance

- cited in PubMed and archived on PubMed Central

- yours - you keep the copyright 